Review

\title{
Systems for Quality Assurance in Pharmacy Education and Training in the European Union
}

Jeffrey Atkinson ${ }^{1, *}$, Bart Rombaut ${ }^{2}$, Antonio Sánchez Pozo ${ }^{3}$, Dimitrios Rekkas ${ }^{4}$, Peep Veski ${ }^{5}$, Jouni Hirvonen ${ }^{6}$, Borut Bozic ${ }^{7}$, Agnieska Skowron ${ }^{8}$, Constantin Mircioiu ${ }^{9}$, Annie Marcincal ${ }^{10}$ and Keith Wilson ${ }^{11}$

1 Pharmacology Department Lorraine University, Pharmacolor Consultants Nancy, 12 rue de Versigny, Villers 54600, France

2 European Association of Faculties of Pharmacy (EAFP), Vrije Universiteit Brussel (VUB), Laarbeeklaan 103, Brussels 1090, Belgium; E-Mail: brombaut@vub.ac.be

3 Faculty of Pharmacy, University of Granada (UGR), Campus Universitario de la Cartuja s/n, Granada 18701, Spain; E-Mail: sanchezpster@gmail.com

4 School of Pharmacy, National and Kapodistrian University Athens, (UoA), Panepistimiou 30, Athens 10679, Greece; E-Mail: rekkas@pharm.uoa.gr

5 Pharmacy Faculty, University of Tartu (UT), Nooruse 1, Tartu 50411, Estonia; E-Mail: peep.veski@ut.ee

6 Pharmacy Faculty, University of Helsinki (UH), Yliopistonkatu 4, P.O. Box 33-4, Helsinki 00014, Finland; E-Mail: jouni.hirvonen@helsinki.fi

7 Faculty of Pharmacy, University of Ljubjana (ULFFA), Askerceva cesta 7, Ljubljana 1000, Slovenia; E-Mail: Borut.Bozic@ffa.uni-lj.si

8 Pharmacy Faculty, Jagiellonian University (JUMC), UL. Golebia 24, Krakow 31-007, Poland; E-Mail: askowron@cm-uj.krakow.pl

9 Pharmacy Faculty, University of Medicine and Pharmacy "Carol Davila” Bucharest (UMFCD-B), Dionisie Lupu 37, Bucharest 020021, Romania; E-Mail: constantin.mircioiu@yahoo.com

${ }^{10}$ Université de Lille 2 (UL), Lille 59000, France; E-Mail: annie.marcincal@pharma.univ-lille2.fr

11 School of Life and Health Sciences, Aston University (AU), Birmingham, B4 7ET, England; E-Mail: k.a.wilson@aston.ac.uk

* Author to whom correspondence should be addressed; E-Mail: jeffrey.atkinson@univ-lorraine.fr; Tel.: +33-383-27-37-03; Fax. +33-383-27-37-03.

Received: 17 October 2013; in revised form: 12 December 2013 / Accepted: 13 December 2013 / Published: 2 January 2014 


\begin{abstract}
With the changes in the Bologna process and the European directive on sectoral professions, the education and training of the pharmacists in the European Higher Education Area is moving towards a quality system based on competences. In this paper we analyze the existing quality assurance and accreditation systems in 10 countries and examine how far these systems have evolved from a resources and curriculum basis towards a competences basis. This is the first step towards the goal of the PHAR-QA project: establishment of a European quality assurance system based on competences. Existing systems of quality assurance for pharmacy education and teaching are based mainly on resources and management not competences. Furthermore, they are national, obligatory, and do not recognize all the current activities of the pharmacists. The PHAR-QA system that will be developed by the consortium of the same name will be based on competences; it will be European, consultative, and will encompass pharmacy practice in a wide sense.
\end{abstract}

Keywords: pharmacy; education; quality assurance; competences

\title{
1. Introduction
}

The establishment of the European Higher Education Area has led universities to harmonize and modernize their educational systems in order to increase mutual recognition needed for student and citizen mobility. The Bologna process is moving from programs based on content and class hours towards programs based on competences [1]. The use of competences and credits leads to harmonization of programs eliminating ambiguity in syllabi and clearly establishing what the student — at the end of the program-is able to do.

All EU pharmacy degree programs follow the European Directive 2005/36 for the recognition of qualifications for sectoral professions and are basically described in terms of content. The definition of the programs in terms of competences is becoming necessary not only because of the changes in the Bologna process, but also because of changes in the role of the pharmacist as defined in the new amendment to the EU directive (see below).

In this paper, we describe the quality assurance and accreditation systems in 10 different countries.

There are several constraints on pharmacy education and training in the European Union that necessitate the development of a new quality assurance system. The reasons for the need for a new system stem from the different points below:

\subsection{EU Directive on Sectoral Professions}

The shortly to be amended [2] EU directive on sectoral professions 2005/36/EC [3] deals with the management (5-year course duration with 6-month training period during or at the end of the course), and knowledge and skills (the word "competence" is not used) required in pharmacy education and training.

Knowledge and skills are developed as follows: 
Course subjects (Annex V.6, 5.61)

(1) Plant and animal biology

(2) Physics

(3) General and inorganic chemistry

(4) Organic chemistry

(5) Analytical chemistry

(6) Pharmaceutical chemistry, including analysis of medicinal products

(7) General and applied biochemistry (medical)

(8) Anatomy and physiology; medical terminology

(9) Microbiology

(10) Pharmacology and pharmacotherapy

(11) Pharmaceutical technology

(12) Toxicology

(13) Pharmacognosy

(14) Legislation and, where appropriate, professional ethics.

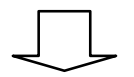

Knowledge and skills (Article 44.3 of the directive).

(1) Adequate knowledge of medicines and the substances used in the manufacture of medicines;

(2) Adequate knowledge of pharmaceutical technology and the physical, chemical, biological and microbiological testing of medicinal products;

(3) Adequate knowledge of the metabolism and the effects of medicinal products and of the action of toxic substances, and of the use of medicinal products;

(4) Adequate knowledge to evaluate scientific data concerning medicines in order to be able to supply appropriate information on the basis of this knowledge;

(5) Adequate knowledge of the legal and other requirements associated with the pursuit of pharmacy.

\subsection{The European Higher Education Area}

The European Higher Education Area ensures more comparable, compatible and coherent systems of higher education in Europe, building on the principles announced in the Bologna declaration [4]. The latter was signed by 29 European countries and is a collection of recommendations, not a directive. One of the Bologna principles recommends that the degree structure be based on a 3-year bachelor followed by a 2-year master degree, with entry and exit possible at the end of the 3-year bachelor degree. With vary rare exceptions this is not possible in pharmacy education; most countries have a 5-year integrated course. Some countries (e.g., Belgium) have an "academic" bachelor in pharmacy that leads automatically to a master in pharmacy.

\subsection{The Diversity of Jobs for Graduates with a Degree in Pharmacy}

Most graduates with a degree in pharmacy take up a career in community pharmacy. The European directive on sectoral professions (above) reflects this situation in defining the knowledge and skills 
required for such practice. The directive does however recognize the existence of hospital pharmacy practice (article 45, Section 2.f of the directive). However, other activities (pharmaceutical industry, pharmaceutical distribution, para-pharmacy, regulatory affairs, laboratory medicine/clinical biology...) are not mentioned in the directive.

\subsection{The Evolution in Healthcare}

Socio-economic changes in healthcare systems are redefining the role of the pharmacist. This is recognized in the proposed amendment to the directive (see [2]) in which the following additions are made:

- Monitoring of medicinal treatments

- Provision of information and advice on health-related issues in cooperation with medical practitioners

- Reporting of adverse reactions of pharmaceutical products

- Personalized support for patients who administer their own medication

- Contribution to institutional public health campaigns

\subsection{The Evolution in the Pharmaceutical Industry}

The pharmaceutical industry has undergone changes in its science (switch to biotechnology, development of therapies for unfulfilled needs like Alzheimer's disease, etc.) and in its economic structure (interactions between universities and start-ups, development of global multinationals, etc.).

It should be noted that the situation regarding points $\mathrm{c}, \mathrm{d}$ and e above may be different from one country to another.

Any system of pharmacy education and training - and the accompanying quality assurance system - should reply intrinsically to the first constraint above but not neglect the four others.

This constitutes the vision for pharmacy practice in Europe.

\section{Methods}

In order to perform a cross-sectional analysis of existing European systems, a questionnaire was sent to the first 10 authors of this report who are partners in the PHAR-QA ("Quality Assurance in European pharmacy education and training”) consortium. This project is financed by the Education, Audio-visual and Culture Executive Agency [5] (EACEA reference 527194-LLP-1-2012-1-BEERASMUS-EMCR). The 11th author in the list is a member of the advisory board.

\section{Results and Discussion}

\subsection{Existing Quality Assurance Systems in Pharmacy Education and Training in 10 Countries of the} European Union I agree

The quality assurance systems in the 10 countries studied showed high variability; it is thus impossible to establish a simple, harmonized pattern.

The main elements of the quality assurance systems are given in Table 1. 
Table 1. The basis and organization of quality assurance systems in $10 \mathrm{EU}$ pharmacy departments.

\section{Country Quality assurance system}

Basis: The auditors check that the university has the resources, structure and management required to ensure that students can acquire adequate competences (generic and pharmaceutical).

Belgium Organization: Flanders has a cross-border agency that deals with Flanders and The Netherlands [6]. In Wallonia the regional "Agence pour l'Evaluation de la Qualité de l'Enseignement Supérieur" [7] handles quality assurance and accreditation, albeit the criteria are the same. There is an audit every seven years (shortly to be changed to five years).

Basis: Evaluation is essentially based on material and human resources together with other elements such as output, results, and an element of appraisal of competences using the European Qualifications Framework. The main reference level descriptors are: skills, competences and knowledge [8].

Spain Organization: Verification and accreditation are done by the national agency ("The National Agency for Quality Assessment and Accreditation of Spain" [9]); in some autonomous regions this task is delegated to a regional agency. To achieve the accreditation and to renew it (every 6 years), evaluation reports have to be presented according to the specific quality assurance system.

Greece Basis: The major criteria for assessing quality fall into four categories: curriculum, teaching, research and other services. Organization: The "Hellenic Quality Assurance Agency for Higher Education (HQAA)" [10] is responsible.

Basis: Evaluation is based mainly on resources. All activities described are evaluated in terms of finances available and the competences of teaching staff.

Organization: The study program in pharmacy is designed, developed and evaluated by the university of Tartu program

Estonia council. The latter consists of the representatives of professional organizations, staff members from other departments and students. The program manager — currently the head of the pharmacy department—is appointed by the university senate. The program manager and council perform an internal evaluation every 3 years. The tools for self-evaluation are developed by the "Estonian Higher Education Quality Agency" [11] and adapted by the university. In addition student organizations undertake an annual official evaluation of the quality of teaching and the competences of the teaching staff.

Basis: The system is based on management and competences. Competences are not "pharmacy-specific".

Organization: The evaluation system is based on national criteria and executed following the advice and under the

Finland supervision of the "Finnish Higher Education Evaluation System (FINHEEC)" [12]. The same principles are applied to all disciplines. Universities develop their own individual systems which are based on FINHEEC standards. Quality assurance systems are audited every 6 years by external examiners nominated by FINHEEC.

Basis: This is essentially on resources. The M. Pharm. program is designed on program structure and partially on needed competences.

Slovenia Organization: The system is national: accreditations of the university and of the program are done by the "Slovenian Quality Assurance Agency for Higher Education" [13]. The system is the same for all programs. Student evaluation is mandatory. Accreditation occurs every 7 years and is based on (a) fulfillment of initial criteria; (b) annual reports for courses; (c) achievement of students' competences; and (d) students' surveys of programs, teacher-student interaction, and courses.

Basis: The quality criteria are: (1) mission, planning and evaluation; (2) organization and administration; (3) curriculum; (4) student and academic policies; (5) staff resources; and (6) facilities and resources - buildings, scientific equipment, financial resources. Generic competencies for all medical specializations are established as well as specific competences for pharmacy.

Poland Organization: The accreditation system is national [14]; the same criteria are used for all universities. Each university has to prepare an accreditation report, which is assessed by an expert panel with independent scientists and experienced academic teachers. 
Table 1. Cont.

\begin{tabular}{|c|c|}
\hline Country & Quality assurance system \\
\hline Romania & $\begin{array}{l}\text { Basis: The evaluation system is based on resources, structures, finances and management. It is not based on } \\
\text { competences. The main areas are: institutional capacity, and educational effectiveness. Within the latter, quality } \\
\text { assurance strategies and procedures are evaluated. } \\
\text { Organization: Verification and accreditation are done by the "National Romanian Agency for Quality Assurance in } \\
\text { Higher Education" [15]. }\end{array}$ \\
\hline France & $\begin{array}{l}\text { Basis. The system is based essentially on resources and management. } \\
\text { Organization: Quality assurance and accreditation are carried out every five years by the independent "French } \\
\text { Evaluation Agency for Research and Higher Education-AERES" [16]. The AERES board is made up of } 25 \text { French, } \\
\text { European or international members appointed by decree. The curriculum is set by the French Ministry of Education } \\
\text { and the organization of courses and examinations is validated by the university council taking into account the } \\
\text { proposals of the faculty council. Internal quality assurance systems are run by certain universities. }\end{array}$ \\
\hline UK & $\begin{array}{l}\text { Basis: There are } 10 \text { standards, some concerned with the process and two with the curriculum and the outcomes. } \\
\text { Standard } 10 \text { is a series of grouped educational outcomes. They are expressed as outcomes rather than competences. } \\
\text { Organization: In the UK the "Quality Assurance Agency for Higher Education" [17,18] sets standards for } \\
\text { universities. Pharmacy is regulated by the "General Pharmaceutical Council" [19,20], an organization set up by } \\
\text { statute and with statutory powers but which is independent of government. The Council sets standards for } \\
\text { pharmacy and pharmacy technician education and has powers both for pre-registration education and post- } \\
\text { registration (the latter currently only used for independent pharmacy prescribers). The council organizes an } \\
\text { accreditation of schools of pharmacy. The council sets the } 10 \text { standards for the education of pharmacists that cover } \\
\text { the university course and the associated one year pre-registration program. }\end{array}$ \\
\hline
\end{tabular}

As a summary of the above table, the system used in most European countries is shown in the diagram (Figure 1).

Figure 1. The organization of the national quality assurance system in $10 \mathrm{EU}$ pharmacy departments.

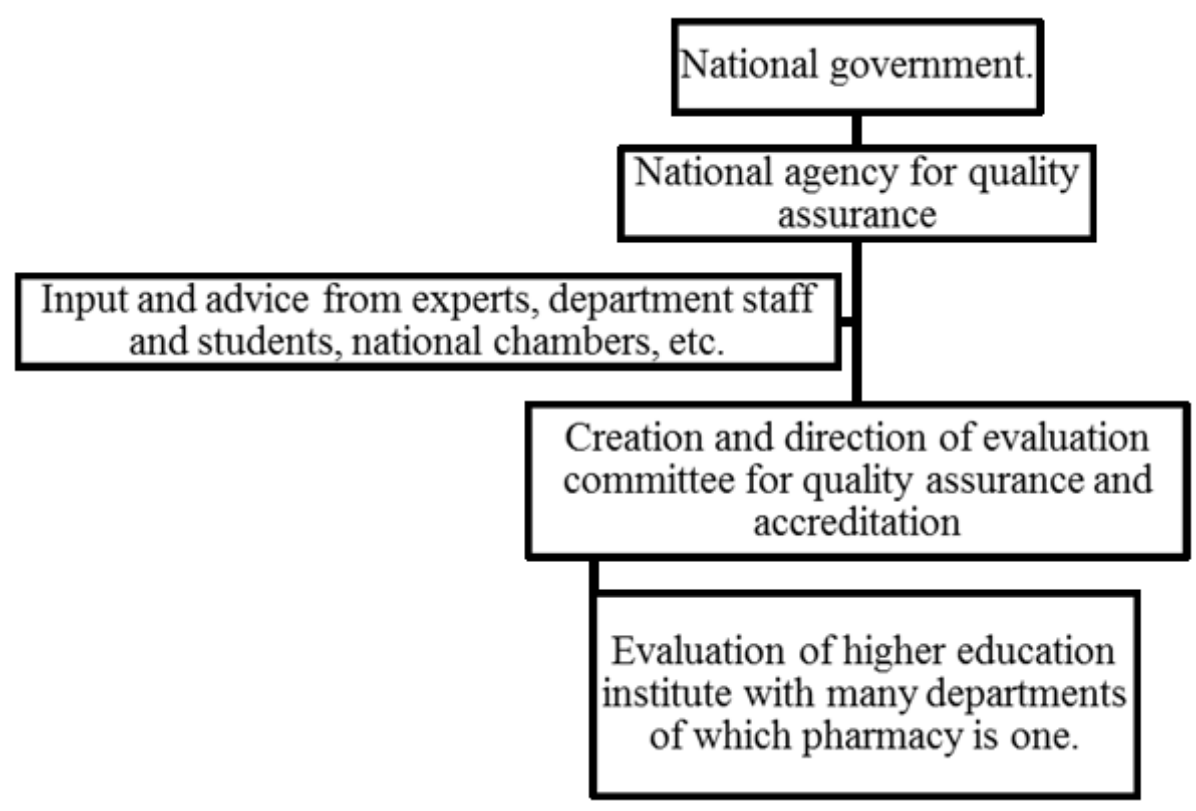

The characteristics of the above system are given in the left-hand column of Table 2. 
Table 2. A comparison of national quality assurance systems with that proposed by the PHAR-QA consortium.

\begin{tabular}{ll}
\hline National quality assurance system. & PHAR-QA system. \\
\hline National & European \\
Based mainly on resources and management & Based on competences \\
Obligatory & Consultative \\
Adapted to national economics and politics in & Adapted to European economics and politics in \\
matters such as healthcare and pharmaceutical & matters such as healthcare and pharmaceutical \\
industry & industry \\
Reviews and applies to a higher educational & Reviews and applies to a pharmacy department \\
institution to which a pharmacy department belongs. & \\
Periodic: $3-7$ year period depending on country & On demand \\
Applies essentially to public institutions & Applies to all institutions both public and private \\
\hline
\end{tabular}

In the right-hand column are the characteristics of the proposed PHAR-QA system; this is shown in Figure 2.

Figure 2. The PHAR-QA project: development of a European quality assurance system based on a competence framework.

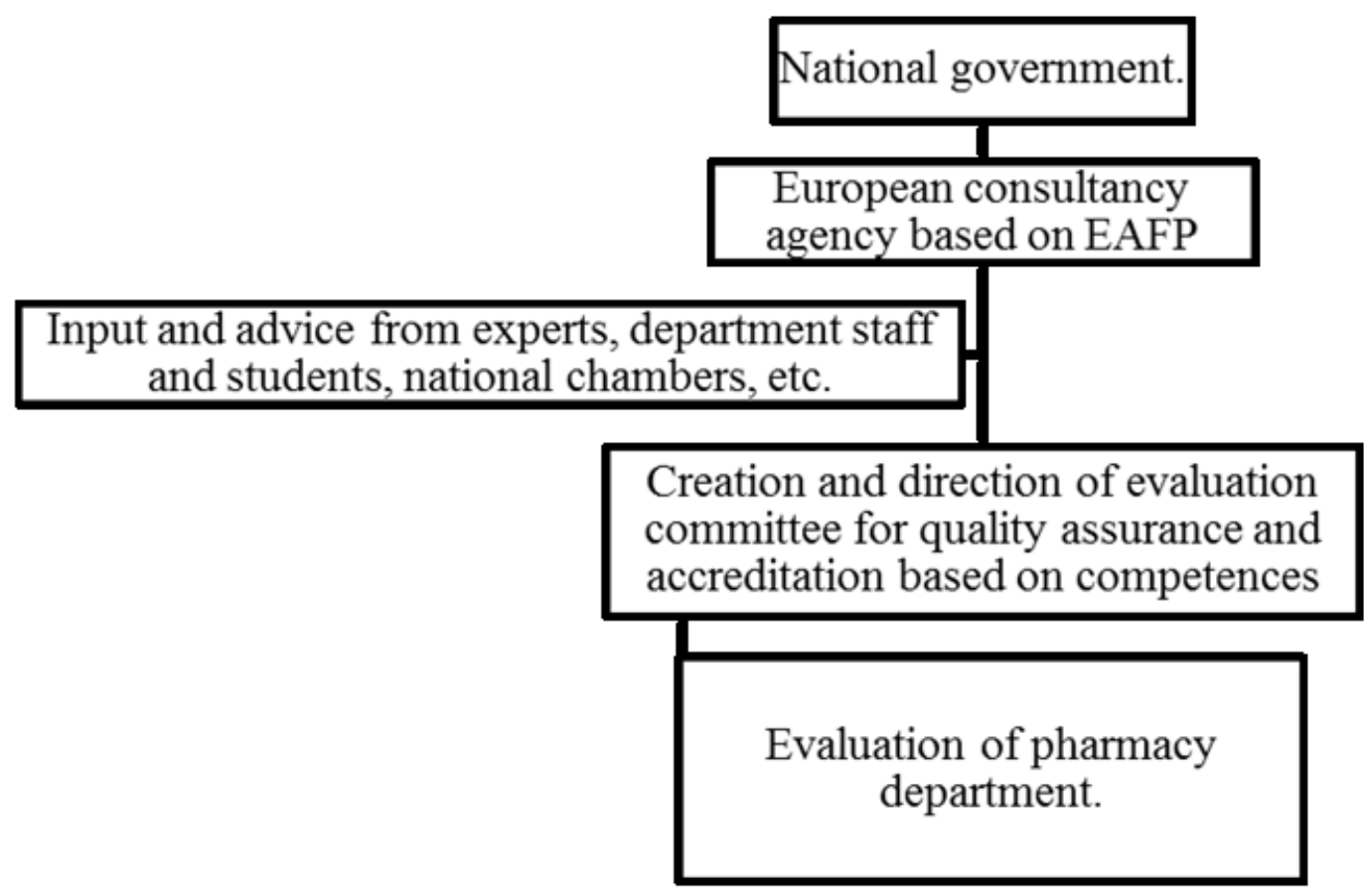

\subsection{Towards a Pan-European System for Quality Assurance in Pharmacy Education and Training} Based on Competences I agree

Our study reveals that the use of competences for quality systems is infrequent.

In the UK, competences for pharmacists have been developed by the "Competency Development and Evaluation Group (CoDEG)" [21] a collaborative network of specialist and academic pharmacists, developers, researchers and practitioners. CoDEG has proposed a "General Level Framework" with competences in patient care, problem solving and management. 
A very similar approach was used by the PHARMINE ("Pharmacy education and training in Europe") network that was funded by the EU [22]. PHARMINE work program 3 was directed by Ian Bates who holds the Chair of Pharmacy Education at the University College London School of Pharmacy, and is Head of Educational Development. The competences his group proposed are available on-line at the PHARMINE website.

The PHAR-QA [23] "Quality assurance in European pharmacy education and training" project follows on from PHARMINE. It is also funded by the EU. PHAR-QA will operate according to the schema shown in Figure 3. Validation and refinement will be done using the Delphi method.

Figure 3. The PHAR-QA "Quality assurance in European pharmacy education and training" project.

Production of a questionnaire on competences based on those set out in PHARMINE WP3 with incorporation of ideas from CoDEG, and MEDINE [24].

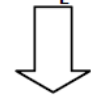

Validation and refinement by the PHAR-QA consortium<smiles>C1CCCC1</smiles>

Validation and refinement by the PHAR-QA European network of pharmacy practitioners (academic staff, students, community, hospital and industrial pharmacists, etc.)

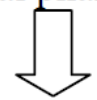

Production of a European framework of competences for pharmacy practice

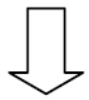

Foundation of a European quality assurance system based on the competency framework

\section{Conclusions}

A review of existing systems of quality assurance for pharmacy education and teaching shows that these are national, obligatory, based mainly on resources and management rather than competences, and adapted to national economics and politics in matters such as healthcare and pharmaceutical industry.

A new system based on competences is required. This is the aim of the PHAR-QA project that will develop a system that is European, consultative, based on competences and adapted to European economics and politics in matters such as healthcare and pharmaceutical industry.

\section{Acknowledgments}

PHAR-QA is funded by the European, Education, Audio-visual and Culture Agency (EACEA: eacea.ec.europa.eu/); the grant number is 527194-LLP-1-2012-1-BE-ERASMUS-EMCR.

\section{Conflicts of Interest}

The authors declare no conflict of interest. 


\section{References}

1. Towards Shared Descriptors for Bachelors and Masters. Available online: http://www.ehea.info/article-details.aspx?ArticleId=110 (accessed on 2 December 2013).

2. Vergnaud, B. Proposal for a Directive of the European Parliament and of the Council Amending Directive 2005/36/EC on the Recognition of Professional Qualifications and Regulation on Administrative Cooperation through the Internal Market Information System. Available online: http://www.europarl.europa.eu/meetdocs/2009_2014/documents/imco/dv/vergnaud_profqual_fina 1report_/vergnaud_profqual_finalreport_en.pdf (accessed on 2 December 2013).

3. Directive 2005/36/ec of the European Parliament and of the Council of 7 September 2005 on the Recognition of Professional Qualifications. Available online: http:/eur-lex.europa.eu/LexUriServ/ LexUriServ.do?uri=OJ:L:2005:255:0022:0142:en:PDF (accessed on 2 December 2013).

4. The European Higher Education Area. Available online: http://www.ehea.info/ (accessed on 2 Decembe 2013).

5. Education, Audio-visual and Culture Executive Agency. Available online: http://eacea.ec.europa.eu/index_en.php (accessed on 2 December 2013).

6. The Accreditation Organization of the Netherlands and Flanders. Available online: http://www.nvao.net/ (accessed on 2 December 2013).

7. Agence pour l'Evaluation de la Qualité de l'Enseignement Supérieur. Available online: http://www.aeqes.be/ (accessed on 2 December 2013).

8. European Qualifications Framework. Available online: http://ec.europa.eu/education/lifelonglearning-policy/eqf_en.htm (accessed on 2 December 2013).

9. The National Agency for Quality Assessment and Accreditation of Spain. Available online: http://www.aneca.es/eng (accessed on 2 December 2013).

10. Hellenic Quality Assurance Agency for Higher Education (HQAA). Available online: http://www.hqaa.gr/ (accessed on 2 December 2013).

11. Estonian Higher Education Quality Agency. Available online: http://www.ekka.archimedes.ee/ (accessed on 2 December 2013).

12. Finnish Higher Education Evaluation System. Available online: http://www.finheec.fi/ (accessed on 2 December 2013).

13. Slovenian Quality Assurance Agency for Higher Education. Available online: http://www.nakvis.si/indexang.html (accessed on 2 December 2013).

14. Polish Accreditation Committee. Available online: http://www.pka.edu.pl/www_en/ (accessed on 2 December 2013).

15. Romanian Agency for Quality Assurance in Higher Education. Available online: http://www.aracis.ro (accessed on 2 December 2013).

16. French Evaluation Agency for Research and Higher Education (AERES). Available online: http://www.aeres-evaluation.fr/ (accessed on 2 December 2013).

17. Quality Assurance Agency for Higher Education. Available online: http://www.qaa.ac.uk/ (accessed on 2 December 2013).

18. Scotland has an independent quality agency. http://www.qaa.ac.uk/Scotland/ (accessed on 2 December 2013). 
19. The General Pharmaceutical Council Operates the Pharmacy Quality Assurance System and This Is a GB Regulator-England, Scotland and Wales. Available online: http:www.pharmacyregulation.org (accessed on 2 December 2013).

20. Northern Ireland has a separate pharmacy regulator - the Pharmaceutical Society of Northern Ireland. This also operates a pharmacy degree Quality Assurance System using the same methodology as the General Pharmaceutical Council. Available online: http://www.psni.org.uk/ (accessed on 2 December 2013).

21. Competency Development and Evaluation Group (CoDEG). Available online: http://www.codeg.org/ (accessed on 2 December 2013).

22. Pharmacy Education and Training in Europe: PHARMINE. 142078-LLP-1-2008-BE-ERASMUSECDSP. Available online: http://www.pharmine.org/ (accessed on 2 December 2013).

23. PHAR-QA "Quality Assurance in European Pharmacy Education and Training". 527194-LLP-12012-1-BE-ERASMUS-EMCR. Available online: http://www.pharmine.org/PHAR-QA/ (accessed on 2 December 2013).

24. The "Medical Education in Europe-MEDINE" Group Developed Competences for Medical Doctors in a Fashion Similar to That of PHAR-QA. Available online: http://medine2.com/ (accessed on 2 December 2013).

(C) 2014 by the authors; licensee MDPI, Basel, Switzerland. This article is an open access article distributed under the terms and conditions of the Creative Commons Attribution license (http://creativecommons.org/licenses/by/3.0/). 